\title{
High-Throughput Genotyping with Single Nucleotide Polymorphisms
}

\author{
Koustubh Ranade, ${ }^{1,10,11,12}$ Mau-Song Chang, ${ }^{2}$ Chih-Tai Ting, ${ }^{3}$ Dee Pei, ${ }^{4}$ \\ Chin-Fu Hsiao, ${ }^{5}$ Michael Olivier, ${ }^{1}$ Robert Pesich, ${ }^{1}$ Joan Hebert, ${ }^{1}$ Yii-Der I. Chen, ${ }^{6}$ \\ Victor J. Dzau, ${ }^{7}$ David Curb, ${ }^{8}$ Richard Olshen, ${ }^{9}$ Neil Risch, ${ }^{1}$ David R. Cox, ${ }^{1}$ and \\ David Botstein ${ }^{1,11,13}$

\begin{abstract}
${ }^{1}$ Department of Genetics, Stanford University School of Medicine, Stanford, California 94305-5120, USA;
${ }^{2}$ Department of Medicine, Veterans General Hospital, Taipei, Taiwan; ${ }^{3}$ Department of Medicine, Veterans General Hospital, Taichung, Taiwan; ${ }^{4}$ Department of Endocrinology and Metabolism, Tri-Service General Hospital, Taipei, Taiwan;

${ }^{5}$ National Health Research Institute, Taipei, Taiwan; ${ }^{6}$ Division of Endocrinology, Stanford University School of Medicine, Stanford, California 94305, USA; 'Department of Medicine, Brigham and Women's Hospital, Boston, Massachusetts 02115, USA; ${ }^{8}$ Hawaii Center for Health Research, Honolulu, Hawaii 96813, USA; ${ }^{9}$ Health Research and Policy, Stanford University
\end{abstract} \\ School of Medicine, Stanford, California 94305, USA
}

To make large-scale association studies a reality, automated high-throughput methods for genotyping with single-nucleotide polymorphisms (SNPs) are needed. We describe PCR conditions that permit the use of the TaqMan or $5^{\prime}$ nuclease allelic discrimination assay for typing large numbers of individuals with any SNP and computational methods that allow genotypes to be assigned automatically. To demonstrate the utility of these methods, we typed $>1600$ individuals for a G-to-T transversion that results in a glutamate-to-aspartate substitution at position 298 in the endothelial nitric oxide synthase gene, and a G/C polymorphism (newly identified in our laboratory) in intron 8 of the 11- $\beta$ hydroxylase gene. The genotyping method is accurate-we estimate an error rate of fewer than 1 in 2000 genotypes, rapid-with five 96-well PCR machines, one fluorescent reader, and no automated pipetting, over one thousand genotypes can be generated by one person in one day, and flexible-a new SNP can be tested for association in less than one week. Indeed, large-scale genotyping has been accomplished for 23 other SNPs in 13 different genes using this method. In addition, we identified three "pseudo-SNPs" (WIAF1161, WIAF2566, and WIAF335) that are probably a result of duplication.

Single-nucleotide polymorphisms, or SNPs, have become prominent in human genetics, and their popularity can be attributed to several reasons. The failure of linkage analysis to identify, in a convincing way, loci for complex diseases has led to interest in large-scale association studies for mapping genes for complex traits (Risch and Merikangas 1996; Collins et al. 1997). Because SNPs are the most abundant, accessible class of polymorphisms present in the human genome, the use of as many as one million SNPs scattered across the human genome was envisioned for such studies. Substantial effort is being devoted by the SNP Consortium toward developing a more modest SNP map comprising 300,000 markers (Masood 1999). The second reason for the current popularity of SNPs is the potential ease with which they can be used for genotyping. In contrast to the tri- and tetranucleotide markers used in linkage analysis, SNPs, because they are usually biallelic, are more amenable to automated detection. This difference could result in considerable savings in the cost and time required for genotyping.

Our group, the Stanford, Asia, Pacific Program for Hyper-

${ }^{10}$ Present address: Pharmaceutical Research Institute, BristolMyers Squibb, Applied Genomics, Princeton, NJ 08543-5400. ${ }^{11}$ Corresponding authors.

12E-MAIL koustubh.ranade@bms.com; FAX (609) 818-5839. 13E-MAIL botstein@genome.stanford.edu; FAX (650) 723-7016. Article published on-line before print: Genome Res., 10.1101/gr. 157801. Article and publication are at http://www.genome.org/cgi/doi/10.1101/ gr.157801. tension and Insulin Resistance (SAPPHIRe), is devoted to identifying susceptibility genes for essential hypertension, a complex trait, in populations of Chinese and Japanese origin. To this end, we have begun a systematic survey of candidate genes that might be involved in regulating blood pressure. Our approach is to identify SNPs in such genes and test these for association in a large population comprised of subjects that have very high or low-normal blood pressure. The general validity of association results needs to be determined by testing the same polymorphism in different populations. The Family Blood Pressure Program (FBPP) of the National Heart, Lung, and Blood Institute, of which SAPPHIRe is a member, was established with this objective in mind. Because members of the FBPP have recruited subjects of diverse origins-from Asian samples like ours, as well as from Caucasian, Hispanic, and African-American populations from the United States-a positive association result in one population can be quickly tested in another. Thus, the FBPP in general, and SAPPHIRe in particular, needed methods to rapidly test different SNPs in a large number of subjects ( $>4000)$. We therefore focused on developing tools that will facilitate high-throughput genotyping using SNPs.

Here we have examined the suitability of the 5 ' nuclease allelic discrimination or TaqMan assay (Livak et al. 1995) for high-throughput genotyping. In this method, the region flanking the polymorphism, typically 100 base pairs, is amplified in the presence of two probes each specific for one or the other allele. Probes have a fluor, called "reporter," at the 5' 
end but do not fluoresce when free in solution because they have a "quencher" at the 3 ' end that absorbs fluorescence from the reporter. During PCR, the Taq polymerase encounters a probe specifically base-paired with its target and unwinds it. The polymerase cleaves the partially unwound probe and liberates the reporter fluor from the quencher, thereby increasing net fluorescence. The presence of two probes, each labeled with a different fluor, allows one to detect both alleles in a single tube. Moreover, because probes are included in the PCR, genotypes are determined without any post-PCR processing, a feature that is unavailable with most other geno-

A

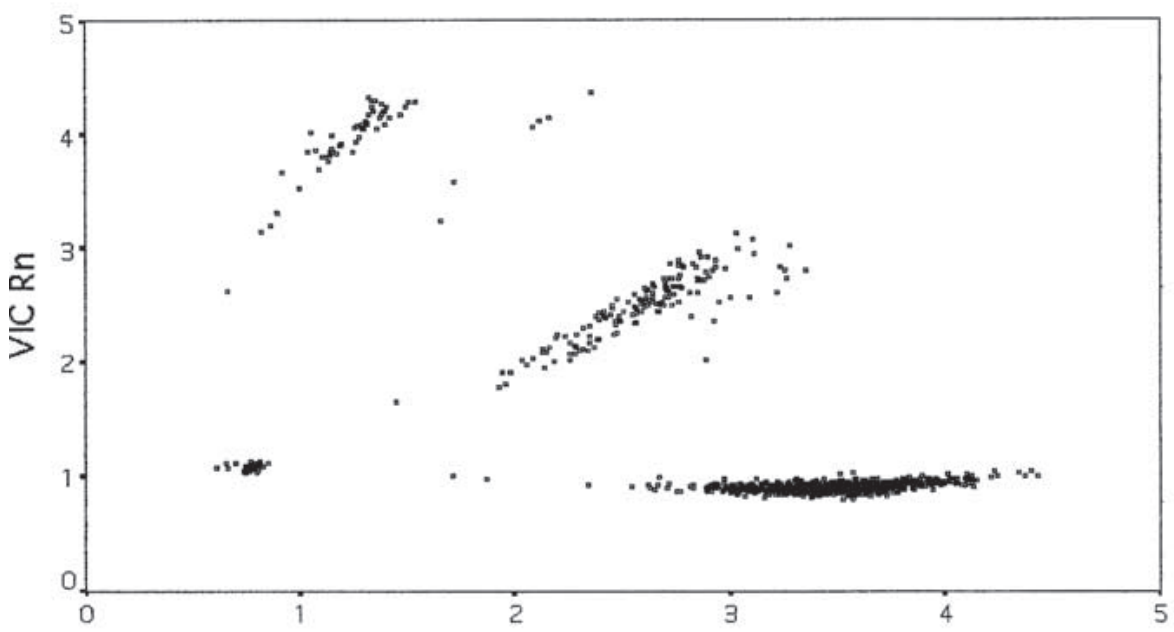

B

FAM Rn

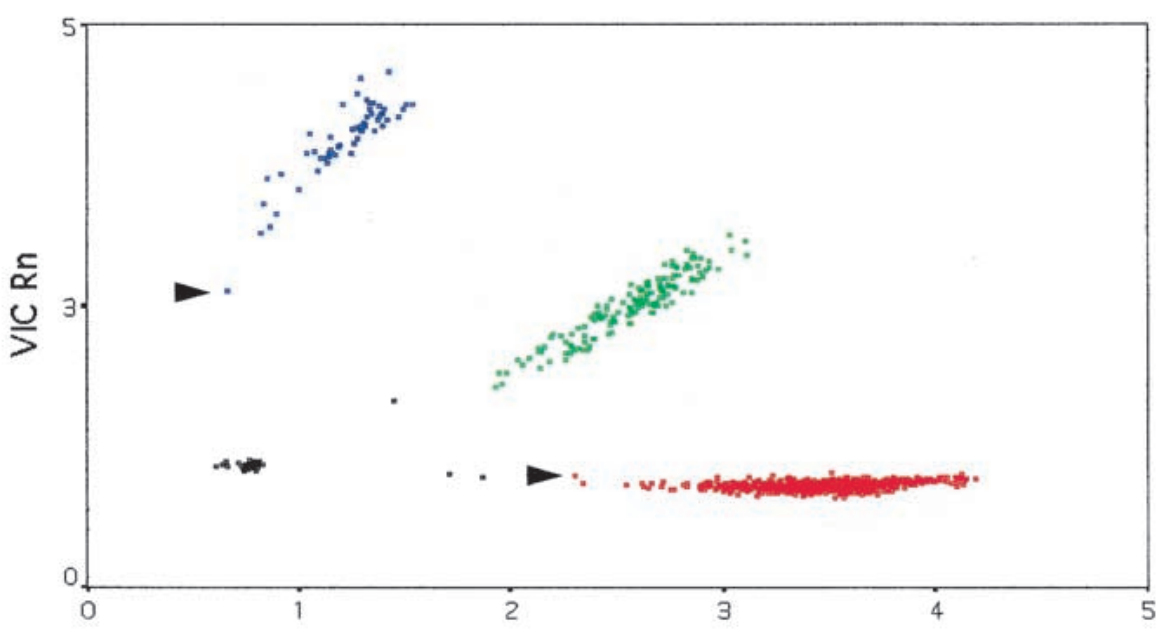

FAM Rn

Figure 1 Genotyping results for the E298D SNP in the endothelial nitric oxide synthase gene. Data for 1699 genotypes are shown. (A) Raw data from the TaqMan PCR. (B) Data corrected for variation in pre-PCR fluorescence and $k$-means clustering. Fluorescence for the $E$ allele is plotted along the $X$-axis (the dye is "FAM") and for the D allele, labeled with the fluor "VIC", along the $Y$-axis. "Rn" is fluorescence from the reporter dye divided by that from the passive reference dye. (Red squares) Samples homozygous for the E allele; (blue squares) samples homozygous for the D allele; (green squares) E/D heterozygotes; (black squares) "no DNA" controls or samples that failed to amplify. Arrows indicate samples with a very low conditional probability of belonging to that particular cluster. typing methods (for a recent review, see Landegren et al. 1998). one to automate the allele-calling procedure-a key requisite for any high-throughput genotyping method. To demonstrate the utility of these methods, we typed $>1600$ subjects another in the 11- $\beta$-hydroxylase gene. In addition, we uncovered three "pseudo-SNPs" that appear to be the result of adjacent duplications.

\section{RESULTS}

High-Throughput Genotyping with the TaqMan Assay

We used the TaqMan assay to type 1699 individuals for two unrelated SNP markers on different chromosomes: One is a $\mathrm{G} / \mathrm{T}$ transversion that results in a glutamate-toaspartate substitution at position 298 in the endothelial nitric oxide synthase gene (eNOSE298D; Miyamoto et al. 1998), and the other is a $\mathrm{C} / \mathrm{G}$ transversion in intron 8 (newly identified in our laboratory) of the 11- $\beta$ hydroxylase gene (CYP11B15). DNA samples and a mixture containing buffer, probes, primers, and polymerase were distributed in 96-well plates and fluorescence in each was measured prior to PCR. Following PCR in a standard 96-well machine, fluorescence was measured again for each sample. Post-PCR data from all the plates were imported into a statistical software package and fluorescence from the two reporters was plotted.

As shown in Figure 1A, for the eNOSE298D SNP, there were no obvious outliers, but samples from one PCR plate formed a separate group. Comparison of mean prePCR fluorescence values for both dyes from this plate with those from other plates revealed that there was significantly less fluorescence from the reporter dyes in all wells of this plate. Because the magnitude of post-PCR fluorescence was proportional to that prior to PCR, we adjusted post-PCR fluorescence for this plate accordingly. $k$ means clustering was then used to automatically classify samples into four groups-the three genotypes and a "no DNA" control group (Fig. $1 \mathrm{~B})$.

The particular $k$-means cluster-
Genome Research www.genome.org
1263 
ing algorithm used for assigning genotypes in this study is based on nearest-centroid sorting (Anderberg 1973; Sharma 1996). In this method, data are classified into a predetermined number of groups or clusters; a case is assigned to the cluster with the smallest distance between the case and the center of the cluster (centroid). Cluster centers are not known in advance but are iteratively estimated from the data. As can be seen (Fig. 1B), the classification is good with no overlap between different genotype clusters. A small number of samples (15) failed to amplify, and the algorithm correctly placed these in the no DNA control group.
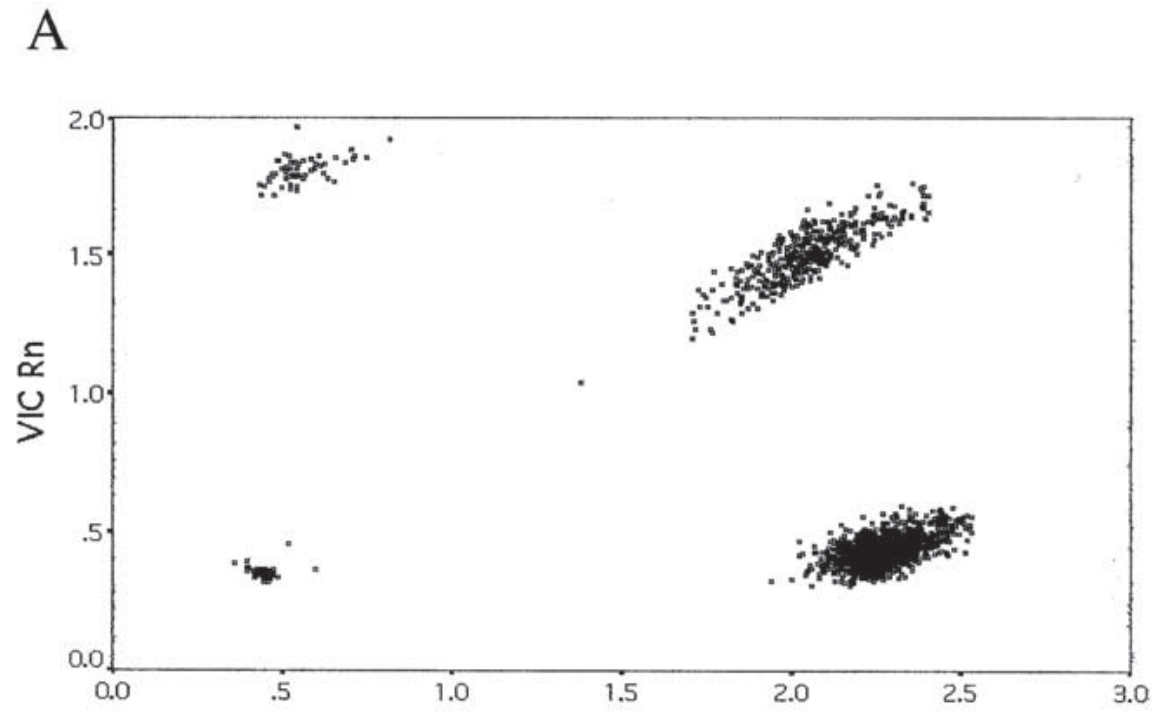

B

FAM Rn

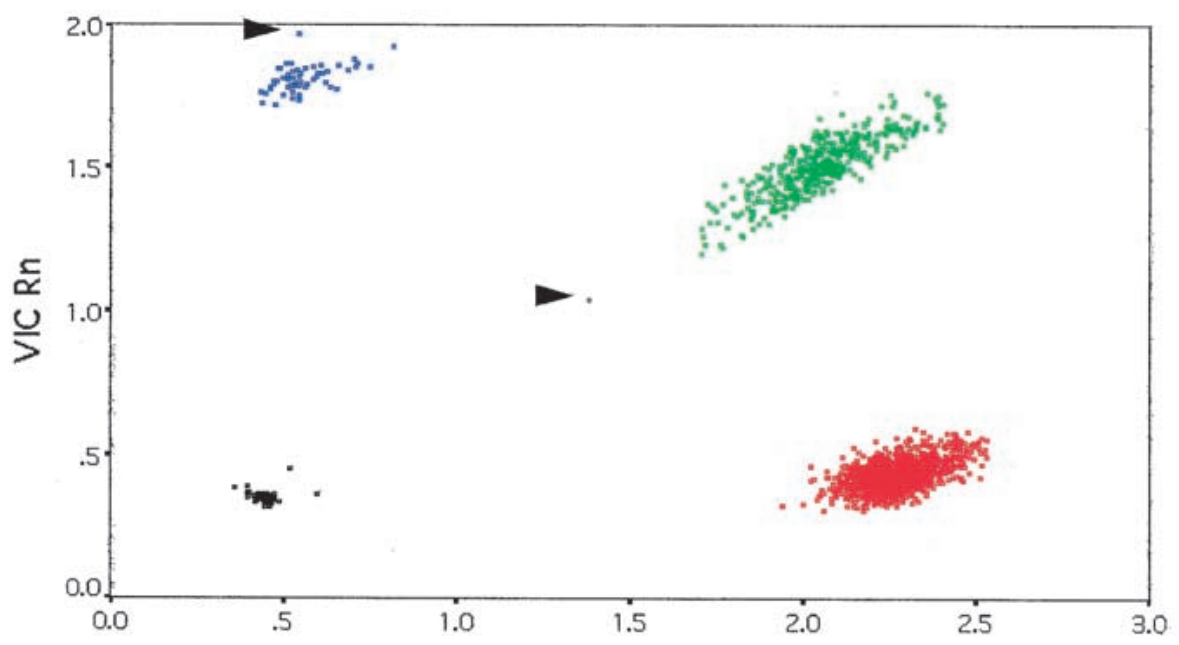

FAM Rn

Figure 2 Genotyping results for the CYP11B15 SNP. Data for 1699 genotypes are shown. (A) Raw data from the TaqMan PCR. (B) Output of the $k$-means clustering. Fluorescence values for the $C$ and $G$ alleles are plotted along the $X$ and $Y$ axes, respectively. (Red squares) C/C homozygotes; (green squares) G/C heterozygotes; (blue squares) G/G homozygotes; (black squares) "no DNA" controls or failed PCRs. Arrows indicate samples with a very low conditional probability of belonging to that particular cluster.
The results for the CYP11B15 SNP are shown in Figure 2. As can be seen from the raw data (Fig. 2A), there were no outliers and, unlike in the eNOSE298D case, all the plates yielded similar post-PCR fluorescence values. The output of the $k$-means clustering is plotted in Figure 2B. For this particular SNP, only four samples failed to amplify robustly and these were classified appropriately in the no DNA control group. For both SNPs, assay failure was probably due to pipetting error because these samples gave robust genotypes for other SNPs.

Over twenty different SNPs (Table 1) have been used for large-scale genotyping using this method and yield results that are similar to those presented here (see www.genome.org for these data).

To monitor the quality of genotyping and allele-calling procedure, $>200$ samples, of which 56 were blind, were typed in duplicate for both SNPs; there were no discordancies. Based on similar genotyping data for SNPs listed in Table 1, we estimate the error-rate to be $<1$ in 2000 genotypes. Further, for the CYP11B15 SNP, for 17 samples we compared TaqMan genotypes to those obtained by direct sequencing. This set of samples included nine $\mathrm{C} / \mathrm{C}$ homozygotes, seven $\mathrm{C} / \mathrm{G}$ heterozygotes, and one G/G homozygote; again, there were no discrepancies.

\section{Detection of Pseudo-SNPs}

In the course of developing TaqMan assays for a genome-wide map of SNPs, we encountered three SNPs (WIAF1161, WIAF2566, and WIAF335) that were apparently not polymorphic-30 unrelated individuals tested were heterozygous (see Fig. 3, Genomic DNA). A trivial possibility is that the probes used in the TaqMan assay failed to distinguish between the two alleles. As can be seen in Figure 3 (Synthetic templates), this is not the case. Synthetic templates carrying one or the other allele were constructed by annealing the appropriate oligonucleotides and "filling in" the resulting partial duplexes. For all three SNPs, the two synthetic alleles can be distinguished from each other by the same probes and primers used to type genomic DNA. Furthermore, artificial heterozygotes made by mixing the two synthetic alleles can be easily distinguished from the two homozygotes.

We hypothesized, therefore, that duplications that differ from one another at a single nucleotide,

\section{Genome Research}


Table 1. Other SNPs Used in Large-Scale Genotyping

\begin{tabular}{|c|c|c|}
\hline Gene & $\begin{array}{l}\text { \# of } \\
\text { SNPs }\end{array}$ & Source \\
\hline Urea transporter & 5 & This lab* \\
\hline Mineralocorticoid receptor & 2 & This lab* \\
\hline CD36 & 1 & This lab* \\
\hline $\begin{array}{l}\text { Angiotensinogen } 2 \\
\text { receptor } 2\end{array}$ & 2 & This lab* \\
\hline $\begin{array}{l}\text { Arginine Vasopressin } \\
\text { receptor }\end{array}$ & 2 & This lab* \\
\hline $\begin{array}{l}\text { Protein tyrosine } \\
\text { phosphatase-1 }\end{array}$ & 1 & $\begin{array}{l}\text { This lab* } \\
\text { Halushka et al. } 1999\end{array}$ \\
\hline Aldosterone synthase & 2 & and this lab \\
\hline Kallikrein & 1 & Halushka et al. 1999 \\
\hline Apolipoprotein C4 & 1 & Halushka et al. 1999 \\
\hline $\begin{array}{l}\beta 3 \text { adrenergic receptor } \\
\text { Intercellular adhesion }\end{array}$ & 1 & Walston et al. 1995 \\
\hline molecule-1 & 1 & Halushka et al. 1999 \\
\hline Alpha adducin & 1 & $\begin{array}{l}\text { Halushka et al. } 1999 \\
\text { McGraw et al. } 1998 \text {; }\end{array}$ \\
\hline $\begin{array}{l}\beta 2 \text { adrenergic receptor } \\
\text { Total }\end{array}$ & $\begin{array}{r}3 \\
23\end{array}$ & Reibsaus et al. 1993 \\
\hline
\end{tabular}

*SNPs newly identified in this laboratory (manuscript in prep.). Genotyping data for these SNPs are available at http:// www.genome.org.

and thus render all individuals heterozygous, had been misinterpreted as SNPs. If this were true, and the duplications were scattered across the genome, then the two alleles would be expected to segregate among cell lines used in radiationhybrid mapping. If, on the other hand, the duplications were in close proximity, then they would be expected to "cosegregate" in the low-resolution mapping panel used here. The results presented in Table 2 show that this latter hypothesis appears to be correct. We typed the Genebridge 4 radiationhybrid mapping panel for the presence or absence of these three pseudo-SNPs and for three others that were polymorphic. For all three pseudo-SNPs, all cell-lines tested harbor both copies of the duplication or neither. In contrast, for markers WIAF2065, 2042, 896, and 610 that are indeed polymorphic, the two alleles "segregate" among the radiationhybrid cell lines-cell lines carry one or the other allele. In the cases of WIAF896, 610, and 2065 a handful of cell lines are "heterozygous" and bear both alleles.

\section{DISCUSSION}

\section{High-Throughput Genotyping with SNPs}

For large-scale association studies to become a reality, highthroughput genotyping methods that are accurate and flexible and use uniform conditions for typing different SNPs will be required. Several methods are currently available that offer the promise of accurate high-throughput genotyping. These include the TaqMan assay (Livak et al. 1995), oligonucleotideligation assays or OLAs (Tobe et al. 1996), minisequencing (Chen and Kwok 1997; Pastinen et al. 1997), molecular beacons (Tyagi et al. 1998), dye-labeled oligonucleotide ligation (Chen et al. 1998), chips (Hacia et al. 1998; Wang et al. 1998), mass spectrometry (Ross et al. 1998), and the invader assay (Mein et al. 2000). These methods, as presently employed, rely on a PCR step to increase the concentration of a segment of DNA sequence carrying the SNP; they diverge in their method of detecting alleles following this amplification step.

TaqMan and molecular beacons, because they incorporate allele-specific probes in the PCR, combine the amplification and detection steps and require no post-PCR processing for determining genotypes-for each reaction, fluorescence is merely measured after PCR and genotypes are inferred based on these values. The other methods, in contrast, require significant post-PCR processing. For instance, in the chip-based method used by Wang et al. (1998), amplified products are purified to remove nucleotides, enzymes, primers, etc. These purified samples are then hybridized for $15 \mathrm{~h}$ to oligonucleotides arrayed on chips; after several additional washing and developing steps, genotypes are determined. In some assays, such as the invader, after amplification, separate reactions are performed to distinguish the two alleles (Mein et al. 2000). These separate reactions could potentially lead to errors because if one reaction fails and the other succeeds, then a heterozygote could be misinterpreted as a homozygote. Although such artifacts can be controlled and many of the post-PCR steps automated, we believe that methods that do not require processing of amplified products are more suited to accurate and high-throughput genotyping. We have, therefore, focused our efforts on one such method-the 5' nuclease allelic discrimination assay or TaqMan. Here we describe tools that make the method accurate, rapid, and flexible, and each of these points is considered below.

We estimate the error-rate to be $<1$ in 2000 genotypes. Two factors contributed to achieving this high level of accuracy: uniform buffer conditions and automated assignment of genotypes. We ensured uniform buffer conditions by using a single large batch of master-mix (i.e., buffer, nucleotides, polymerase, probes, and primers mixture) for typing all of the samples for a given SNP. We have found that small differences in buffer conditions, such as might result from errors pipetting into individual wells or plates, cause variation in postPCR fluorescence values. It turned out to be the general case that applying the correction factor derived from the relative pre-PCR fluorescence of the several plates being compared (exemplified in Fig. 1A,B) deals well with this problem. Thereafter, we could pool data across different plates and thereby fully automate the procedure for assigning genotypes. Genotypes are assigned automatically using $k$-means clustering. This method of allele-calling eliminates human bias and allows one to assign a "quality score" to each genotype. This score is the probability that a particular sample falls within a genotype class given its fluorescence values for each reporter dye. If fluorescence values within a cluster are approximately normally distributed, then calculating this probability is straightforward-it is simply the probability of observing a certain value given a bivariate normal density (see Methods). As shown in Figures 1B and 2B, a few samples (three and two, respectively) have a low probability of belonging to the assigned cluster using this criterion. To our knowledge, this is the first time that $k$-means clustering coupled with a quality score has been used in assigning genotypes at SNPs.

The particular $k$-means clustering algorithm implemented here is not foolproof. Egregious outliers with very high or very low fluorescence values, which can result, for example, from contaminants in the DNA, defeat the clustering algorithm and result in classification that is obviously wrong. We note, however, that cursory visual examination of a plot of the data can usually identify these outliers.

The conditions for PCR used here- $900 \mathrm{nM}$ each primer, 
Genomic DNA
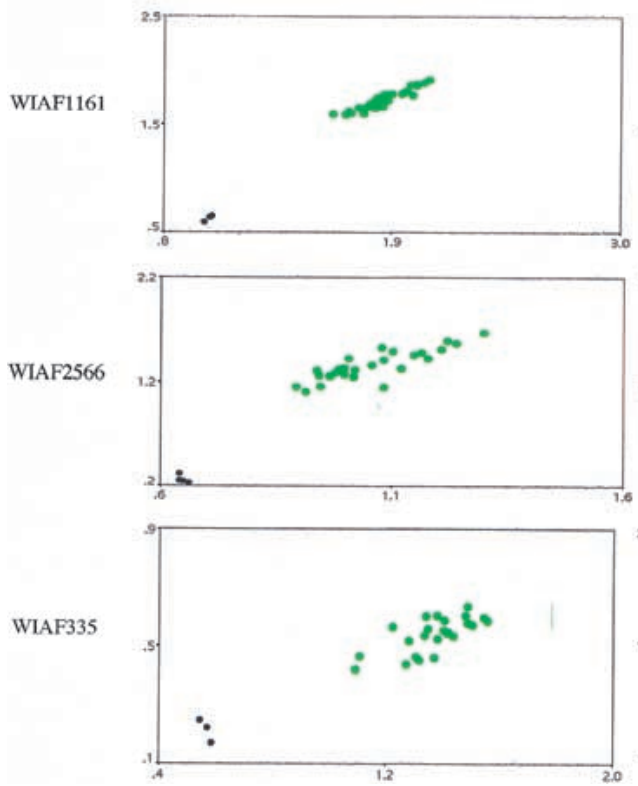

Synthetic Templates
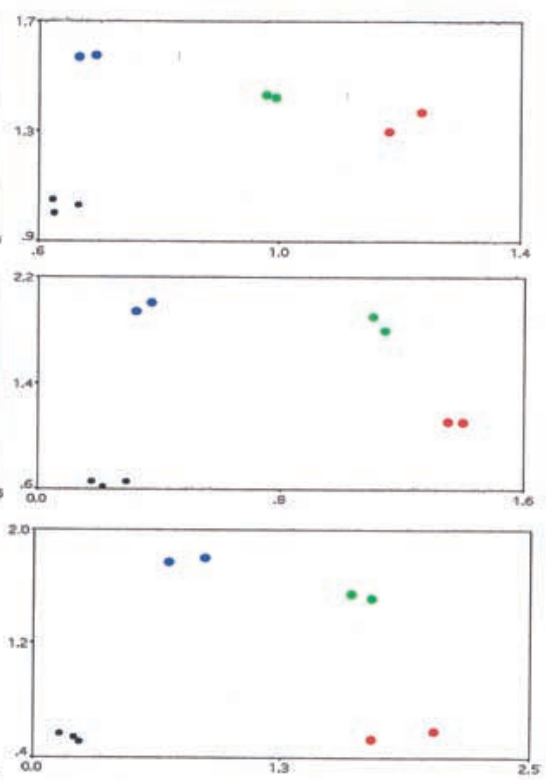

Figure 3 Pseudo-SNPs. (Left) Genomic DNA from 25-30 individuals was typed for the indicated SNPs. The axes are as in Figs. 1 and 2. Green dots are inferred to be heterozygotes; homozygotes are conspicuously absent. (Right) Synthetic templates bearing one (red dots) or the other allele (blue dots) were typed in duplicate using the same probes and primers used at left. Heterozygotes made by mixing equal amounts of homozygotes are shown in green.

$250 \mathrm{nM}$ each probe, and an annealing/extension temperature of $62^{\circ} \mathrm{C}$-are, with minor modifications, generally applicable. One parameter, the annealing/extension temperature needs to be optimized for each new SNP. We generally test two temperatures, $62^{\circ} \mathrm{C}$ and $64^{\circ} \mathrm{C}$, for a new SNP. With improvements in programs that calculate melting temperatures, we expect that even this step can be eliminated. Over 20 different SNPs (Table 1) have been used for large-scale genotyping under these conditions, and yield results that are similar to those

Table 2. Radiation Hybrid Analysis

\begin{tabular}{|c|c|c|c|c|}
\hline SNP & $\begin{array}{l}\text { Allele } 1, \\
\text { but not } \\
\text { Allele } 2, \\
\text { positive }^{\text {a }}\end{array}$ & $\begin{array}{l}\text { Allele } 2, \\
\text { but not } \\
\text { Allele 1, } \\
\text { positive }^{\text {a }}\end{array}$ & $\begin{array}{c}\text { Allele } 1 \\
\text { and } \\
\text { Allele } 2 \\
\text { positive }^{\mathrm{a}}\end{array}$ & Polymorphic $^{\mathrm{b}}$ \\
\hline WIAF2065 & 17 & 13 & 2 & yes \\
\hline WIASF896 & 22 & 22 & 5 & yes \\
\hline WIAF610 & 15 & 9 & 2 & yes \\
\hline WIAF2042 & 11 & 15 & 0 & yes \\
\hline WIAF1161 & 0 & 0 & 35 & no \\
\hline WIAF2566 & 0 & 0 & 28 & no \\
\hline WIAF335 & 0 & 0 & 38 & no \\
\hline
\end{tabular}

${ }^{a}$ The number of radiation-hybrid cell-lines scoring positive on the Genebridge 4 panel is given. Cell-lines were typed using the TaqMan assay and scored by comparing the signal to that obtained from hamster DNA or a sample containing no DNA. The total number of cell-lines in the panel is 93 .

${ }^{b}$ Markers were considered polymorphic if heterozygotes and at least one class of homozygotes were detected in a sample of 30 individuals of Chinese descent. If only heterozygotes were detected, the marker was considered nonpolymorphic. presented here. These uniform conditions make the assay flexible and enable one to accommodate a new SNP easily. With five 96-well PCR machines, one fluorescent reader and no automated pipetting, $>1000$ genotypes can be generated by one person in one day. Thus, in our hands, once a new SNP is identified, a large-scale association study with 2000 samples can be performed in less than a week. With more PCR machines and automated pipetting stations, we expect that the throughput could be increased by at least an order of magnitude.

The genotyping routine described here is suitable for typing large numbers of individuals for selected SNPs in tens or even hundreds of candidate genes. However, there are two impediments to the use of TaqMan, as implemented here, for whole-genome association studies: the amount of DNA used in the PCR and the cost per genotype. If $30 \mathrm{ng}$ of DNA are used for typing each SNP, then a genome scan with 300,000 SNPs will require a minimum of $9 \mathrm{mg}$ of DNA, an amount far in excess of that available from typical blood samples obtained at clinics. We estimate that the cost of reagents per TaqMan genotype is $\sim \$ 1.50$; at this price, a whole-genome scan for 2000 individuals with 300,000 SNPs will cost almost one billion US dollars. Clearly, the amount of DNA and the cost per genotype will need to be reduced significantly for whole-genome association studies to become practical.

For the TaqMan method we can envision at least two improvements. First, the PCR can be miniaturized, perhaps to nanoliter volumes $(25 \mu \mathrm{L}$ reactions were used in this study), thereby decreasing the cost of reagents and conserving precious DNA samples. A thousand-fold reduction in volume would bring the assay into a scale that might be both feasible and affordable. Second, with improvements in TaqMan chemistry (e.g., probes with higher specificity) it should be possible to genotype pools of DNA, as opposed to individual samples as was done here, thus further conserving reagents and effort. An alternative method to determining allele frequencies in pools of DNA is to run the TaqMan assay in real time (Germer et al. 2000). However, for high-throughput genotyping, this approach would require a large number of expensive fluorescent readers. A limitation of the pooling method is that individual genotypes would not be provided, thus complicating analyses of haplotypes.

To conclude, we believe that the TaqMan assay is technically adequate for fully automated genotyping of SNPs on a scale required for genome-wide association studies, provided only that further miniaturization to a nanoliter scale is carried out. We have used the current implementation to genotype $\sim 1700$ individuals for tens of markers and have found the method to be robust in daily use. To our knowledge, this is the first time that a method for typing SNPs has been assessed on such a large scale. Furthermore, the automated allele-calling 
procedure we have implemented should be generally applicable to any fluorescence-based genotyping method.

\section{METHODS}

\section{Genotyping}

The PrimerExpress program (Perkin-Elmer, Applied Biosystems Division) was used to design probes and primers. For the eNOSE289D SNP the approximate melting temperatures of probes and primers were $67^{\circ} \mathrm{C}$ and $61^{\circ} \mathrm{C}$, respectively. For the CYP11B15 SNP, probes and primers were calculated to have melting temperatures of $\sim 70^{\circ} \mathrm{C}$ and $62^{\circ} \mathrm{C}$, respectively. The sequences of the primers and probes used in this study are given in Table 3 . Each $25 \mu \mathrm{L}$ PCR contained $30 \mathrm{ng}$ of genomic DNA, $900 \mathrm{nM}$ primers, $250 \mathrm{nM}$ probes, and $12.5 \mu \mathrm{L}$ of TaqMan Universal PCR master mix (Perkin-Elmer, Applied Biosystems Division), which is a solution containing buffer, Uracil-N-glycosylase, deoxyribonucleotides, uridine, passive reference dye (ROX), and TaqGold DNA polymerase. We found that, for authentic SNPs, over $90 \%$ of the TaqMan assays we tested under these conditions give usable genotypes without further optimization of the assay. We have also found that as little as $100 \mathrm{nM}$ probes can be used in the PCR reaction, with results that are comparable to those presented here. For consistently poolable results (see below), it was found necessary to type all subjects for a given SNP with a single lot of PCR master mix. Amplification was done under the following conditions: $50^{\circ} \mathrm{C}, 2 \mathrm{~min} ; 95^{\circ} \mathrm{C}, 10 \mathrm{~min}$; followed by 40 cycles of $94^{\circ} \mathrm{C}, 15 \mathrm{sec}$ and $62^{\circ} \mathrm{C}, 1 \mathrm{~min}$ in a Perkin-Elmer 9600 thermocycler. Fluorescence in each well was measured before and after PCR using a ABI 7700 machine (Perkin Elmer, Applied Biosystems Division). Patient population has been described previously (Ranade et al. 2000).

\section{Statistical Analyses}

Normalized fluorescence values (Rn), defined as the amount of fluorescence from each reporter dye divided by that from the reference dye, were imported into a statistical software package (SPSS version 6.1). To correct for pipetting errors, fluorescence values were measured prior to the PCR. In prin- ciple, prior to PCR all wells of all of the plates should have equal amounts of fluorescence from either reporter or reference dyes. In practice, however, because of variation in pipetting, these amounts tend to vary and eventually cause predictable variation in post-PCR fluorescence values. To account for these pre-PCR differences, mean fluorescence values prior to PCR for each reporter dye were calculated for each plate. If the mean value of a particular plate is significantly different from the others, as judged by a non-parametric Wilcoxon signed-ranks test, then post-PCR values for that particular plate are adjusted accordingly. For this study, only one plate of samples needed to be adjusted for the eNOSE298D SNP (see Fig. 1).

$k$-means clustering was used to classify data into four groups. In this method of partitioning the data, cases are assigned to a predetermined number of groups. In this case, the number of groups is the number of genotype classes-threeand a no DNA control group. Squared Euclidean distances were used in the clustering, and cluster centers were estimated iteratively from the data. Fifty iterations were permitted, but clustering was terminated after only four iterations because there was no change in cluster centers.

If one assumes that the distribution of fluorescence values within a cluster is approximately bivariate normal, then the conditional probability $\left(\mathrm{P}_{\mathrm{i}}(\mathbf{x})\right)$ that a sample with particular Rn values (x) falls within a particular cluster or genotype class is given by the formula:

$$
P_{i}(\mathbf{x})=\frac{1}{2 \pi \sqrt{\left|\mathbf{E}_{i}\right|}} \exp \left\{-\frac{1}{2}\left(\mathbf{x}-\mathbf{m}_{i}\right)^{T} \mathbf{E}_{i}^{-1}(\mathbf{x}-\mathbf{m})\right\}
$$

where $\mathbf{E}_{\mathrm{i}}$ is the covariance matrix for the $i$ th cluster, $\left|\mathbf{E}_{\mathrm{i}}\right|$ is the determinant of the covariance matrix, $\mathbf{m}_{\mathrm{i}}$ is the mean vector for the $i$ th cluster, and $\mathrm{T}$ denotes the transpose of the vector. If the normality assumption is invalid, then the distribution can be modeled as a mixture of more than one normal distribution, and the conditional probability calculated based on this new distribution. Bayesian posterior probabilities that take into account prior probabilities can also be calculated using this framework (Sharma 1996), probably with little added benefit, however.

Table 3. Probes and Primers

\begin{tabular}{|c|c|c|}
\hline SNP & Probes $^{a}$ & Primers $^{\mathbf{b}}$ \\
\hline \multirow[t]{2}{*}{ eNOSE298D } & CCCCAGATGAGCCCCCAGAACT & CGGTCGCTTCGACGTGCT \\
\hline & CCCCAGATGA $\overline{\underline{T}} \mathrm{CCCCCAGAACTC}$ & CCAGTCAATCCCTTTGGTGCT \\
\hline \multirow[t]{2}{*}{ CYP11B15 } & TCTCCCAGTACCCGGTCTGCCCA & TACACAGCCTCAACCTGGCC \\
\hline & 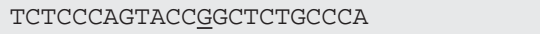 & GGCCTGCATGTTTCCTGGA \\
\hline \multirow[t]{2}{*}{ WIAF2065 } & AACAAGCTTTCC音CTCCCACTTCCCT & CAAGCATTTGTCTTAATTTACAGACATTAA \\
\hline & ACAAGCTTTCCGCTCCCACTTCC & GTGGATGAAGAGGTTGAGGTGATA \\
\hline \multirow[t]{2}{*}{ WIAF896 } & CCAAAATTCCGAGTCCCTTGGCT & TCTGCCTATAGCTTGGATATCTTAATCTCT \\
\hline & CAGCCAAAATTCCTAGTCCCTTGGCT & CTGAGAGGTTTTGGAATGACTTGAA \\
\hline \multirow[t]{2}{*}{ WIAF610 } & TCTGGGTATGTGAC̄ATGCCTGCTCC & АСTCTGAATTATGGCAGTAGGCAAA \\
\hline & TGGGTATGTGACGTḠCCTGCTCC & СTTGAGAGAACTCATCATTTAAAAATGTGT \\
\hline WIAF2042 & $\begin{array}{l}\text { TCTATCTCTAAGGGGAGTCTCAAAACCCCA } \\
\text { TCTATCTCTAAGGGEAGTCTCAAAACCCCA }\end{array}$ & TGAGCACATTTCTTGGGTCTGTT \\
\hline \multirow[t]{2}{*}{ WIAF1161 } & САTTATGTGGACTGÄACCGACTTTTCTAAAGC & ATGAGCATTAGCTACTTTTCAGAATTGA \\
\hline & $\begin{array}{l}\text { CATTATGTGGACTGAAT्TEGACTTTTCTAAAGCT } \\
\text { C }\end{array}$ & TGTTGCAAAAGGAAAGAAAAGCTT \\
\hline \multirow[t]{2}{*}{ WIAF2566 } & TGTGCATAGTATCCATTAGTTTTTCATGATCCA & ACTCAGAAGGGTCATGGGTGA \\
\hline & TGTGCATAGTATCCAGGTAGTTTTTCATGATCCA & GCTTCTAGGGTATCCATCTCCCTAGTA \\
\hline \multirow[t]{2}{*}{ WIAF335 } & TGTTAACAATTTT $\underline{G G G}$ CAGCCGAACT & GGATGTTGCATAAATTCAGGTTCTTT \\
\hline & TGTTAACAATTTTTGGCAGCCGAACTC & ATGTGCGTTTGTAGACAGCATCA \\
\hline
\end{tabular}

aprobes used in the TaqMan assay. The SNP is underlined.

bForward and reverse primers for each TaqMan assay, with the forward primer listed first. Sequences for the SNPs prefixed WIAF were obtained from the Whitehead Institute Web site (http://www-genome.wi.mit.edu). 


\section{Radiation Hybrid Analysis}

The Genebridge 4 panel (Research Genetics) was used to analyze pseudo-SNPs. The primers and probes used to detect each SNP are listed in Table 3. PCR conditions were as described above, except that $25 \mathrm{ng}$ of DNA from each radiation-hybrid cell line was used and PCR was done using an ABI 7700 machine. Following PCR, fluorescence values were read on the same machine and each cell line was scored for the presence or absence of signal from either reporter.

For SNPs WIAF1161, WIAF2566, and WIAF335, synthetic templates bearing one or the other allele were constructed as follows. The "top" oligonucleotide ( 40 nucleotides) was annealed to two "bottom" oligonucleotides ( 70 nucleotides), which differed from each other at the single polymorphic nucleotide. Annealing was carried out in a $100 \mu \mathrm{L}$ volume containing $2 \mu \mathrm{M}$ of each oligonucleotide, $10 \mathrm{mM}$ Tris at $\mathrm{pH}$ $7.5,6 \mathrm{mM} \mathrm{MgCl}_{2}, 50 \mathrm{mM} \mathrm{NaCl}$, and $5.76 \mathrm{mM} \beta$-mercaptoethanol. After denaturing the oligonucleotides at $95^{\circ} \mathrm{C}$ for 1 min, the solution was slowly cooled to room temperature. Five units of Klenow polymerase were added and the reaction was incubated at room temperature for $20 \mathrm{~min}$. The reaction was stopped by adding EDTA to a final concentration $10 \mathrm{mM}$ and heating to $70^{\circ} \mathrm{C}$ for $20 \mathrm{~min}$. One or two $\mu \mathrm{L}$ of a $10^{-3}$ or $2 \times 10^{-3}$ dilution of this solution was used in the TaqMan PCR.

\section{ACKNOWLEDGMENTS}

We thank subjects for participating in this study. Ken Livak and Mike Lucero of Perkin-Elmer, Applied Biosytems Division, helped greatly with the TaqMan assays. This paper is written on behalf of members of the Stanford, Asia, and Pacific program for Hypertension and Insulin resistance (SAPPHIRe). We thank Susan Old, Steve Mockrin, and Cashell Jaquish of the National Heart, Lung, and Blood Instittute (NHLBI) for helpful discussions. This work is funded by a grant from the Family Blood Pressure Program of the NHLBI, National Institutes of Health.

The publication costs of this article were defrayed in part by payment of page charges. This article must therefore be hereby marked "advertisement" in accordance with 18 USC section 1734 solely to indicate this fact.

\section{REFERENCES}

Anderberg, M.R. 1973. Cluster analysis for applications. Academic Press, New York.

Chen, X. and Kwok, P.Y. 1997. Template-directed dye-terminator incorporation (TDI) assay: A homogeneous DNA diagnostic method based on fluorescence resonance energy transfer. Nucleic Acids Res. 25: 347-353.

Chex, X., Livak, K.J., and Kwok, P.Y. 1998. A homogeneous ligase-mediated DNA diagnostic test. Genome Res. 8: 549-556.

Collins, F.S., Guyer, M.S., and Chakravarti, A. 1997. Variations on a theme: Cataloguing human DNA sequence variation. Science 278: $1580-1581$.

Hacia, J.G., Sun, B., Hunt, N., Edgermon, K., Mosbrook, D., Robbins, C., Fodor, S.P., Tagle, D.A., and Collins, F.S. 1998. Strategies for mutational analysis of the large multiexon ATM gene using high-density oligonucleotide arrays. Genome Res. 8: 1245-1258.

Halushka, M.K., Fan, J.B., Bentley, K., Hsie, L., Shen, N., Weder, A., Cooper, R., Lipshutz, R., and Chakravarti, A. 1999. Patterns of single-nucleotide polymorphisms in candidate genes for blood-pressure homeostasis. Nature Genet. 22: 239-247.
Germer, S., Holland, M.J., and Higuchi, R. 2000. High-throughput SNP allele-frequency determination in pooled DNA samples by kinetic PCR. Genome Res. 10: 258-266.

Landegren, U., Nilsson, M., and Kwok, P.Y. 1998. Reading bits of genetics information: Methods for single-nucleotide polymorphism analysis. Genome Res. 8: 769-776.

Livak, K.J., Marmaro, J., and Todd, J.A. 1995. Towards fully automated genome-wide polymorphism screening. Nature Genet. 9: $341-342$.

Lyamichev, V., Mast, A.L., Hall, J.G., Prudent, J.R., Kaiser, M.W., Takova, T., Kwiatkowski, R.W., Sander, T.J., de Arruda, M., Arco, D.A. et al. 1999. Polymorphism identification and quantitative detection of genomic DNA by invasive cleavage of oligonucleotide probes. Nature Biotechnol. 17: 292-296.

Masood, E. 1999. . . As consortium plans free SNP map of human genome. Nature 398: 545-546.

McGraw, D.W., Forbes, S.L., Kramer, L.A., and Liggett, S.B. 1998. Polymorphisms of the $5^{\prime}$ leader cistron of the human $\beta 2$-adrenergic receptor regulate receptor expression. J. Clin Invest. 102: $1927-1932$.

Mein, C.A., Barratt, B.J., Dunn, M.G., Siegmund, T., Smith, A.N., Esposito, L., Nutland, S., Stevens, H.E., Wilson, A.J., Phillips, M.S., et al. 2000. Evaluation of single nucleotide polymorphism typing with invader on PCR amplicons and its automation. Genome Res. 10: 330-343.

Miyamoto, Y., Saito, Y., Kajiyama, N., Yoshimura, M., Shimasaki, Y., Nakayama, M., Kamitani, S., Harada, M., Ishikawa, M., Kuwahara, K., et al. 1998. Endothelial nitric oxide synthase gene is positively associated with essential hypertension. Hypertension 32: $3-8$.

Pastinen, T., Kurg, A., Metspalu, A., Peltonen, L., and Syvanen, A.C. 1997. Minisequencing: A specific tool for DNA analysis and diagnostics on oligonucleotide arrays. Genome Res. 7: 606-614.

Ranade, K., Hsuing, A.C., Wu, K.D., Chang, M.S., Chen, Y.T., Hebert, J., Chen, Y.I., Olshen, R., Curb, D., Dzau, V., Botstein, D., Cox, D., and Risch, N. 2000. Lack of evidence for an association between alpha-adducin and blood-pressure regulation in Asian populations. Amer. J. Hyper. 13: 704-709.

Reihsaus, E., Innis, M., MacIntyre, N., and Liggett, S.B. 1993. Mutations in the gene encoding for the b2-adrenergic receptor in normal and asthmatic subjects. Amer. J. Respir. Cell Mol. Biol. 3: 334-339.

Risch, N. and Merikangas, K. 1996. The future of genetic studies of complex human diseases. Science 13: 1516-1517.

Ross, P., Hall, L., Smirnov, I., and Haff, L. 1998. High level multiplex genotyping by MALDI-TOF mass spectrometry. Nature Biotechnol. 16: $1347-1351$.

Sharma, S. 1996. Applied Multivariate Techniques. John Wiley \& Sons, New York.

Tobe, V.O., Taylor, S.L., and Nickerson, D.A. 1996. Single-well genotyping of diallelic sequence variations by a two-color ELISA-based oligonucleotide ligation assay. Nucleic Acids Res. 24: $3728-3732$.

Tyagi, S., Bratu, D.P., and Kramer, F.R. 1998. Multicolor molecular beacons for allele discrimination. Nature Biotechnol. 16: 49-53.

Walston, J., Silver, K., Bogardus, C., Knowler, W.C., Celi, F.S., Austin, S., Manning, B., Strosberg, A.D., Stern, M.P., Raben, N., et al. 1995. Time of onset of non-insulin-dependent diabetes mellitus and genetic variation in the $\beta 3$-adrenergic-receptor gene. N. Engl. J. Med. 333: 343-347.

Wang, D.G., Fan, J.B., Siao, A., Berno, C.J., Young, P., Sapolsky, R., Ghandour, G., Perkins, N., Winchester, E., Spencer, J., et al. 1998. Large-scale identification, mapping, and genotyping of single nucleotide polymorphisms in the human genome. Science 280: $1077-1082$.

Received August 2, 2000; accepted in revised form April 2, 2001. 


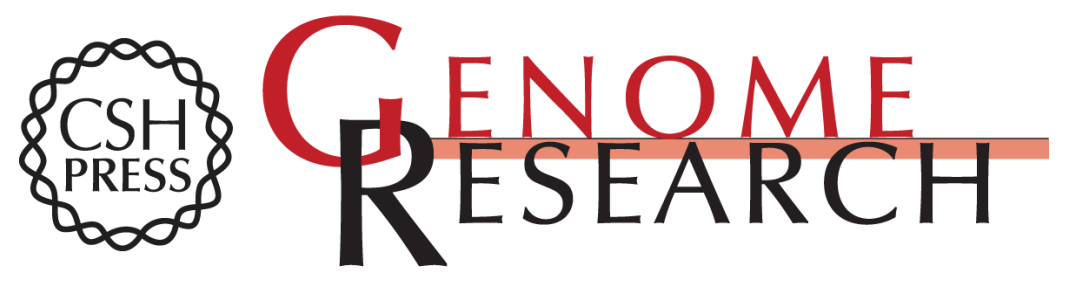

\section{High-Throughput Genotyping with Single Nucleotide Polymorphisms}

Koustubh Ranade, Mau-Song Chang, Chih-Tai Ting, et al.

Genome Res. 2001 11: 1262-1268

Access the most recent version at doi:10.1101/gr.157801

Supplemental http://genome.cshlp.org/content/suppl/2001/07/11/11.7.1262.DC1

Material

License

Email Alerting Receive free email alerts when new articles cite this article - sign up in the box at the Service top right corner of the article or click here.

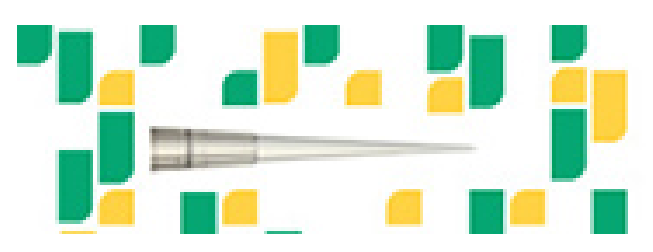

To subscribe to Genome Research go to: https://genome.cshlp.org/subscriptions 